\title{
An Autoradiographic Study of Muscular Dystrophy, Motor Neuron Disease and Charcot-Marie-Tooth Disease
}

\author{
GEORGE MONCKTON AND HALYNA MARUSYK
}

SUMMARY: The autoradiographic findings using tritiated leucine are described in muscle biopsy material from five patients with progressive muscular dystrophy (P.M.D.), three with motor neuron disease (M.N.D.) and four with Charcot-Marie-Tooth disease (C.M.T.). In progressive muscular dystrophy there is a marked increase in uptake of leucine into cytoplasmic proteins and precursors, and reduced incorporation into structural protein. In Charcot-Marie Tooth disease muscle there is a significantly increased uptake into cytoplasmic

RÉSUMÉ: Nous décrivons les observations autoradiographiques avec leucine tritiée de biopsies musculaires provenant de cinq patients atteints de dystrophie musculaire progressive (P.M.D.), de trois patients atteints de maladies $d u$ neurone moteur (M.N.D.), et de quatre patients atteints de Charcot-MarieTooth (C.M.T.). Les résultats montrent que dans la dystrophie musculaire progressive il y a une augmentation marquée de la captation de la leucine dans les protéines cytoplasmiques et leurs précurseurs, réduisant d'autant l'incorporation à même la protéine structurale. Dans le muscle de patients atteints de la maladie de CharcotMarie-Tooth, il y a une augmentation elements and a normal uptake into structural protein. In motor neuron disease the uptake into cytoplasmic elements appears normal but is reduced into structural proteins.

The abnormal uptake in C.M.T. could be explained as a product of regenerative efforts associated with reinnervation. However, the abnormal uptake may represent the primary effects of gene action in the muscle, as seems probable in progressive muscular dystrophy

significative de la captation par les éléments cytoplasmiques et une captation normale au niveau de la protéine structurale. Pour ce qui est des maladies du neurone moteur, la captation dans les éléments cytoplasmiques semble normale, mais elle est diminuée dans les protéines structurales.

La captation anormale dans le C.M.T. pourrait s'expliquer comme le résultat d'une effort régénératif associé à une réinnervation. Toutefois, la captation anormale pourrait aussi représenter les premiers effets de l'action génétique au niveau du muscle, tout comme probablement dans la dystrophie musculaire progressive.
In recent years there has been increasing interest in the relationship between the primary myopathies and disease of the peripheral nervous system. While the earlier writings on the dystrophies suggested a primary muscle and a neurogenic basis for these diseases, there is now evidence of a neural factor in all the dystrophies save the Duchenne type. Concerning the Duchenne dystrophy, there are conflicting views. McComas and his fellow workers (McComas et al., 1970, 1971b, c, d, 1974) have built up a strong, though incomplete argument favoring a significant neural component. Thomson and Sweetin (1974) concluded in a study of creatine phosphokinase levels of patients and carriers that the dystrophic process could not be accounted for on a purely neural basis, whereas a myopathic hypothesis could account for their findings and the myocardial affection commonly seen in these patients. In the course of observing, by autoradiography, the incorporation of ${ }^{3} \mathrm{H}$ leucine into proteins and their precursors in muscle from progressive muscular dystrophy (P.M.D.) patients, we showed an increase in incorporation into cytoplasmic elements and a lower incorporation into structural protein. Similar studies were carried out on muscle from patients with motor neuron disease (M.N.D.) and the incorporation behavior of ${ }^{3} \mathrm{H}$ leucine paralleled the normal control muscle results. These findings appeared to suggest that a fundamental difference existed in the incorporation processes in dystrophic and chronically denervated muscle, as shown in motor neuron disease.

To elucidate this we decided to examine the incorporation of
Supported by the Muscular Dystrophy Associa-

tion of Canada.

From the University of Alberta, Edmonton, Alberta, Canada.

Reprint requests to: Dr. G. Monckton, 9101 Clinical Sciences Building, University of Alberta, Edmonton, Alberta, Canada T6G 1S2. 
tritiated leucine into individual muscle fibers in progressive muscular dystrophy (P.M.D.) and motor neuron disease (M.N.D.) and Charcot-Marie-Tooth (C.M.T.) as an example of a genetically determined neurogenic amyotrophy.

\section{METHODS}

Motor point biopsies were obtained from five patients with P.M.D., three with M.N.D. and four patients with C.M.T. disease. Normal muscle was obtained from ten patients undergoing surgery for chronic non-infective orthopedic problems. Fragments $(0.5 \mathrm{gm}$.) of the muscle biopsy specimen were placed in an isotope mixture containing $0.9 \mathrm{ml}$. human serum and $100 \mu$ $\mathrm{Ci}$ of ${ }^{3} \mathrm{H}(\mathrm{G})$ L-leucine (Amersham Searle). The muscles were incubated at $37^{\circ} \mathrm{C}$. for an hour and rinsed in normal saline. Each specimen was then divided into portions for routine light and electron microscopy, autoradiography and for glycerination. The method of Szent-Gyorgyi (1947) was used for glycerination. The specimen was placed in a $50 \%$ aqueous solution of glycerol containing 4 $\mathrm{mM}$ ethylenediaminotetraacetate adjusted to $\mathrm{pH} 7$, and stored at $4^{\circ} \mathrm{C}$. for 24 hours, and then transferred into a fresh glycerol solution and stored at $-20^{\circ}$ C. for three weeks. The muscle was then rinsed in a solution of $100 \mathrm{mM}$ potassium chloride and 10 $\mathrm{mM}$ dibasic phosphate $(\mathrm{pH}$ 7.0) for one hour at $4^{\circ} \mathrm{C}$. This process was undertaken to rid the muscle cells of soluble protein and cell sap, thus leaving only structural protein with incorporated radio-isotope for subsequent autoradiographic study.

Both the glycerinated and nonglycerinated muscle specimens were fixed in 3\% gluataraldehyde and phosphate buffer at $\mathrm{pH} \mathbf{7 . 2}$ for two hours, post-fixed in $1 \%$ osmium tetroxide in phosphate buffer for one hour, dehydrated in ethanol and embedded in Epon 812 (Ladd); 0.5\% 2,5 diphenyloxazole (PPO) Amersham Searle) was added to the propylene oxide/Epon mixture of the embedding procedure. The Epon blocks were polymerized at $60^{\circ} \mathrm{C}$. for 48 hours.
Thick $(1 \mu)$ sections were cut and mounted on glass slides previously subbed with an aqueous solution of $0.5 \%$ gelatin and $0.05 \%$ chrome alum. The slides were dried and dipped in Ilford L4 nuclear emulsion and kept in light tight containers at $4^{\circ}$ C. The slides were developed after three to five days, the sections were stained with a saturated aqueous solution of phenylenediamine and examined by light microscopy. Grain counts over $250 \mu^{2}$ were made over one micron thick sections of dystrophic, motor neuron disease and Charcot-Marie-Tooth muscle in glycerinated and non-glycerinated material. The counts were made with a standard eye piece grid and random areas of sections were counted. The results were assimilated into histograms. Cross sections of the same material were photographed and individual fibers noted and grain counts made. The areas of the identified cross sectioned fibers were determined by tracing with transparent squared paper. Cross sections of the muscle were stained for myosin adenosinetriphosphatase at $\mathrm{pH} 10.4$ and 4.6 to determine fiber types and relative involvement of them.

\section{RESULTS}

Examination of the dystrophic patients' muscle biopsies showed typical changes of progressive muscular dystrophy. These consisted of variations in fiber size, disruption and central nucleation of fibers, evidence of regeneration as seen by basophilic staining in $\mathrm{H}$ and $\mathrm{E}$ preparations, and large fleshy nuclei with prominent nucleoli.

Characteristic denervation changes were seen in the motor neuron disease patients' muscle with group fiber atrophy and some variation of fiber size, with little evidence of fibrosis. The muscle obtained from the Charcot-Marie-Tooth patients also showed evidence of neurogenic atrophy with some fiber hypertorphy.

Histochemical staining for myosin ATPase at $\mathrm{pH} 10.4$ and $\mathrm{pH} 4.6$ showed mixed fiber involvement in all cases, but in C.M.T. there was a

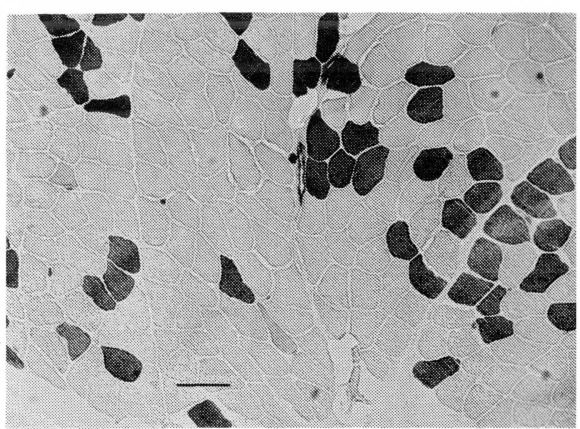

Figure 1-Cross section of muscle from patient, age 14 , with Charcot-MarieTooth disease. Myosin ATPase pH 10.4. Note preponderance of Type I fibers. Scale: $100 \mu$.

preponderance of Type I fibers (Fig. 1) in some cases.

\section{Autoradiography}

The histogram (Fig. 2) shows a marked difference in uptake of the ${ }^{3} \mathrm{H}$ leucine in P.M.D. as compared to the normal and M.N.D. group. The Charcot-Marie-Tooth patients' muscle incorporated ${ }^{3} \mathrm{H}$ leucine to a significantly greater extent than normal or motor neuron disease patients' muscle, but to a lesser extent than the progressive muscular dystrophy patients. After glycerination it is seen that M.N.D. and P.M.D. have similar low incorporation of ${ }^{3} \mathrm{H}$ leucine; C.M.T. is also moderately reduced. Grain counts were carried out over cross sections of the biopsies as described in the methods.

Figure 3 shows the fiber size distribution for the muscle examined, and indicates the shift to the left of fiber populations in C.M.T. and progressive muscular dystrophy. In motor neuron disease, however, there is a more or less equal representation of fiber sizes.

Figure 4 shows the plot of grain counts to fiber size and shows a good agreement with the bulk grain counts in Figure 2. It also indicates a linear relationship of fibers cross sectional area to grain count in all cases. It will be noted, however, that there is some divergence of the graphs so that progressive muscular dystrophy and Charcot-Marie-Tooth disease, while appearing to be roughly parallel are divergent from 


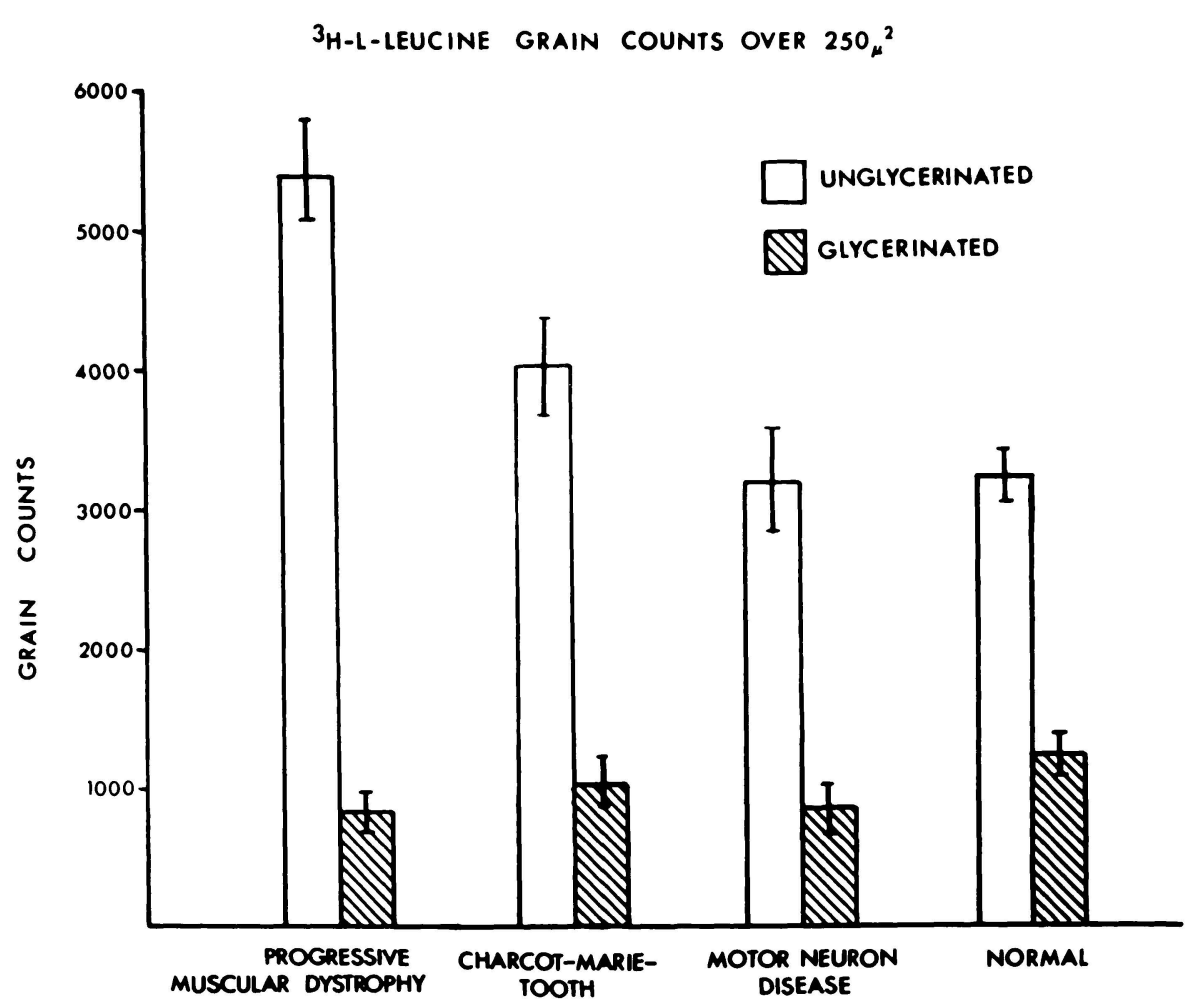

Figure 2-Histogram showing the means of grain counts over $250 \mu 2 /$ longitudinal section from normal M.N.D., Dystrophic and C.M.T. patients in unglycerinated and glycerinated muscle. Bars represent \pm S.D. $P=0.01$.

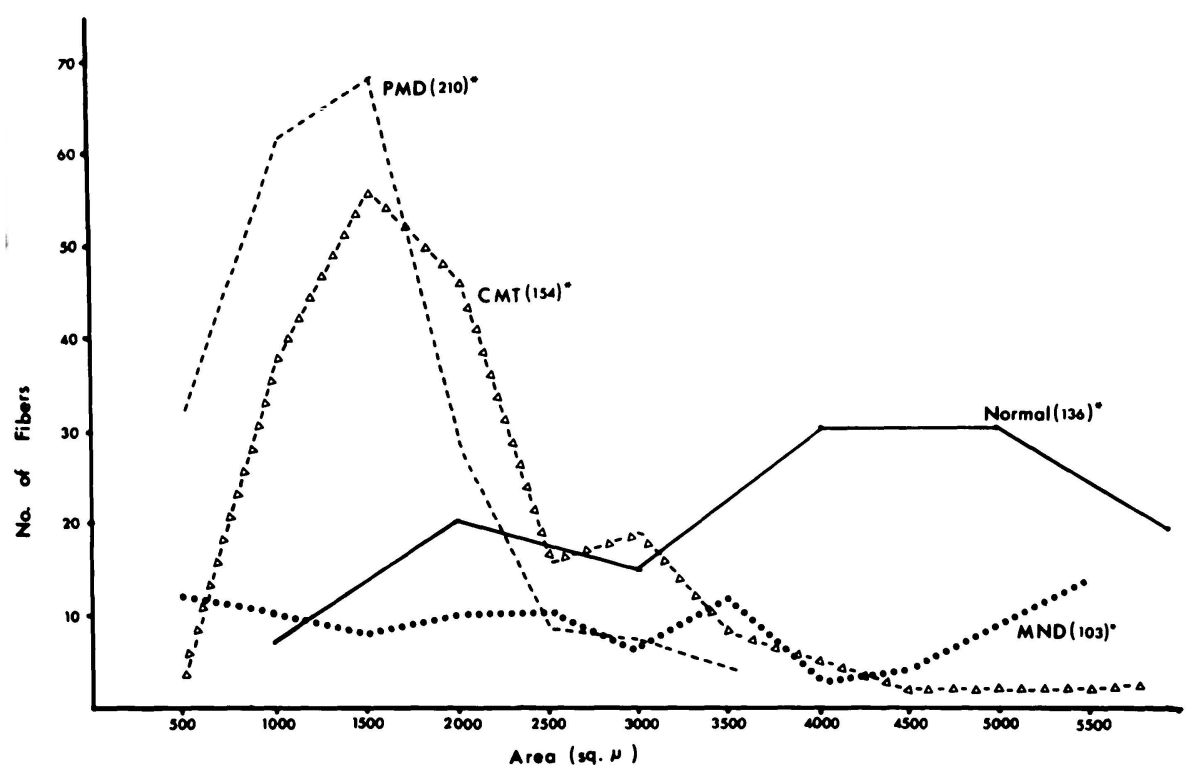

Figure 3-Graph of fiber cross sectional areas of normal and from patients with M.N.D., P.M.D. and C.M.T. Note shift to left in dystrophic and C.M.T. fiber sizes.

* Total number of fibers in sample. that of the normal and motor neuron disease.

\section{DISCUSSION}

At the outset it must be conceded that single pulse incorporation studies do not necessarily indicate a persistent activity status in a given organism, and that the amount of activity expressed by uptake of an amino acid depends on many factors that cannot be assessed. In human disease such experiments have to be conducted against a background of an amino acid pool of unknown proportions. The only constants that can be applied are those that the experimenter can impose such as dosage and duration of exposure, size of specimens and general tissue management. Bearing these possibilities in mind, the present series of biopsy studies were carried out under as near standard conditions as possible. The results obtained show a difference from normal in the uptake of ${ }^{3} \mathrm{H}$ leucine in the cases of progressive muscular dystrophy and Charcot-Marie-Tooth disease.

In progressive muscular dystrophy the changes are similar to those reported by us in the dy mouse (129reJ) (Monckton and Marusyk, 1975). There is a two to two and one-half times increase in uptake into cytoplasmic protein and precursors, and a marked reduction of structural protein incorporation. This latter was shown by Nihei et al., (1973) to be due to a reduction of myosin synthesis. It is important to point out that the amino acid pool is normal in the dystrophic mouse (Kitchin and Watts, 1973) and while no figures are available for man, the same situation may apply. Time course studies would be very helpful but are hardly feasible in the dystrophic patient In the mouse, Kitchin and Watts showed an initial increase in cytoplasmic uptake that levels out after 12 hours to approximately normal. Our studies show a similar increase in uptake in human dystrophy in the first hour.

In the Charcot-Marie-Tooth patients there appears to be an increased uptake of ${ }^{3} \mathrm{H}$ leucine into cytoplasmic elements. Cytoplasmic uptake is significantly higher than 


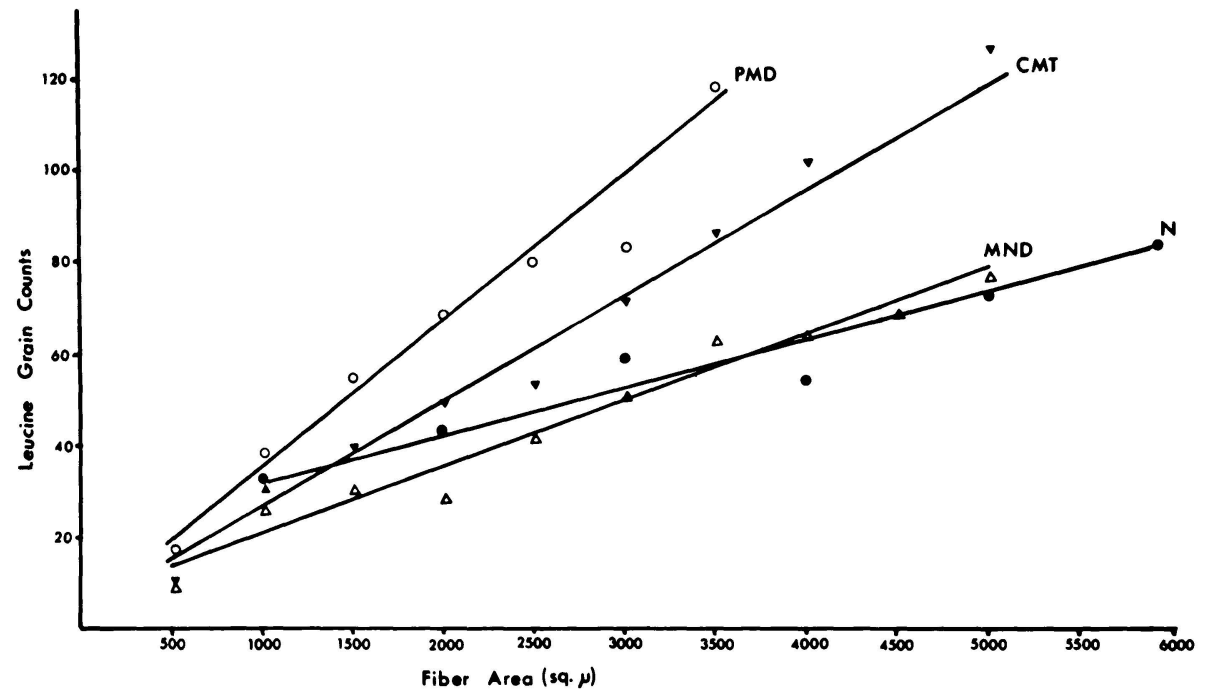

Figure 4-x/y plot of the mean of grains counted/cross sectional fiber area in patients with P.M.D. and M.D. and C.M.T. contrasted with the normal ${ }^{3} \mathrm{H}(\mathrm{G})$ L-leucine uptake.

normal and less than that of the dystrophic patients. Structural protein uptake is slightly less than normal. In motor neuron disease patients the tritiated leucine uptake is normal in muscle fibers of normal size, but by extrapolation is probably reduced in the very small fibers as it is in the Charcot-Marie-Tooth patients. As we noted in the results, Charcot-Marie-Tooth and the dystrophic grain counts over cross sections show some parallelism in the count per fiber size graph, and these are noted to be divergent towards the larger fiber end of the spectrum. It seems likely that there is, in the larger fibers, both the noted increased uptake together with the effects of hypertrophy, and we think that the synthesis drive of hypertrophy is reflected in a greater grain density per unit area than in some of the smaller fibers.

If one accepts the findings and differences described in these experiments, it becomes necessary to make an attempt to explain them with an hypothesis. In an earlier paper we suggested that the difference in uptake between dystrophic and motor neuron disease muscle argued for a difference in underlying cause of the disease, in favor of a myogenic basis for progressive muscular dystrophy (Monckton and Marusyk, 1976). While this may be true, the findings in our patients with Charcot-Marie-Tooth disease suggest some alternatives.

Although recent authors considered the amyotrophy of CharcotMarie-Tooth disease to be due to a neuropathy, it is noteworthy that a number of authors (Haase and Shy, 1960; Engel, 1967b; Mumenthaler, 1970) have questioned the facility with which the differentiation may be made. While it is true that the advent of modern histochemistry has helped to eliminate some of the problems in differentiation there may yet be room for a mixed neuromyopathic group of disorders. Such a situation could explain the aberrant (as compared to motor neuron disease) tritiated leucine uptake we see in Charcot-Marie-Tooth disease).

A further consideration in comparing Charcot-Marie-Tooth to motor neuron disease is that this disease is regarded as a peripheral or die-back neuropathy whereas motor neuron disease is seen as an example of a perikaryon disorder. It could be argued that in Charcot-Marie-Tooth the demonstration of axoplasmic flow abnormalities might provide for atypical neuromyotrophism. Brimijoin, Capek and Dyck (1973) have shown such changes in the autonomic nerves in this condition. In motor neuron disease the ictus of the disease appears to be in the perikaryon and this, as has been shown by Pleasure et al., (1969) in experimental neuropathy, may cut off trophic factors, at least to the periphery of the axon. If one can accept the argument with regard to Charcot-Marie-Tooth that the muscle changes are brought about by neural trophic effects, the question has to be faced as to why such an explanation does not account for similar changes, although to a greater degree, in progressive muscular dystrophy. It is conceivable that progressive muscular dystrophy might be an extreme example of neurotrophism in muscle. As we have shown (Monckton and Nihei, 1969), the abnormal uptake of isotope in progressive muscular dystrophy is related to an abnormal ribosomal activity at all stages of the disease, and would appear to support gene action in the muscle itself.

It could be argued that the uptake in C.M.T. is due to attempts at regeneration described by Tomé et al., (1976), which would also agree with the increased terminal innervation ratio described by Coers (1976).

Finally, the abnormal uptake in Charcot-Marie-Tooth disease and in muscular dystrophy may, as in any genetically determined disorder, indicate another facet of the pleomorphic expression of a single gene.

\section{REFERENCES}

BRIMIJOIN, S., CAPEK, P. and DYCK, P. J. (1973). Axonal transport of Dopamine hydroxylase by human sural nerves in vitro. Science 180: 1295-1297.

COERS, C. (1976). Changes in Motor Unit pattern in the Charcot-Marie peroneal muscular atrophy as compared to spinal muscular atrophy. In press IV. Journees Internationales De Pathologie NeuroMusculaire.

ENGEL, W. K. (1967b). Muscle biopsies in neuromuscular diseases. Pediatric Clinics of America. 24: 963-995.

HAASE, G. R. and SHY, G. M. (1960). Pathological changes in muscle biopsies from patients with perineal muscular atrophy. Brain 83: 631-637.

KITCHIN, S. E. and WATTS, D. C. (1973). Comparison of the turnover patterns of total and individual proteins in normal mice and those with hereditary muscular dystrophy. Biochem. J. 136: 1017-1028. 
McCOMAS, A. J., SICA, R. E. P. and CURRIE, S. (1970). Muscular dystrophy: evidence for a neural factor. Nature, 226: 1263-1264.

McCOMAS, A. J., SICA, R. E. P and CAMPBELL, M. J. (1971a). "Sick" motoneurons. A unifying concept of muscle disease. Lancet, 1: 321-325.

McCOMAS, A. J., SICA, R. E. P. and CURRIE, S. (1971d). An electrophysiological study of Duchenne dystrophy. J. Neurol. Neurosurg. Psychiat. 34: 461-468.

McCOMAS, A. J., SICA, R. E. P. and UPTON, A. R. M. (1974b). Multiple muscle analysis of motor units in muscular dystrophy. Archives of Neurology, 30: 249-251.

MONCKTON, G. and MARUSYK, H. (1975). ${ }^{3} \mathrm{H}$ leucine incorporation in myofib- rils of normal and dystrophic mouse skeletal muscle. Canad. J. of Neurol. Sci. 2: 1-4.

MONCKTON, G. and MARUSYK, H. (1976). Myofibrillar incorporation of ${ }^{3} \mathrm{H}(\mathrm{G})$ L-leucine in progressive muscular dystrophy and motor neuron disease. Neurol. 26: $234-237$

MONCKTON, G. and NIHEI, T (1969). A correlation of histology and amino acid incorporation studies in Duchenne muscular dystrophy. Neurol. 19: 415-418.

NIHEI, T, TATARYN, D. and FILIPENKO, C. (1971). The reduction of myosin synthesis in muscle of dystrophic mice. In: Basic Research in Myology $p$. 204, Exerpta Medica. Amsterdam.

PLEASURE, D. E., MISHLER, K. C. and ENGEL, W. K. (1969). Axonal transport of proteins in experimental neuropathies. Science. 166: 524-525.

ROGERS, A. W. (1969). Techniques of autoradiography New York, Elsevier Publishing Co.

SZENT-GYORGYI, A. (1947). Chemistry of muscle contraction. New York, Academic Press.

THOMSON, W H. S. and SWEETIN, J C. (1974). The neurogenic and myogenic hypothesis in human (Duchenne) muscular dystrophy Nature 249: 151-152.

TOMÉ, F. M. S. and FARDEAU, M. (1976). Muscle and nerve biopsies studies in Charcot-Marie-Tooth disease. In press, IV Journees Internationales De Pathologie Neuro-Musculaire. 